\title{
The bactericidal and fungicidal effects of salicid on pathogenic organisms involved in hospital infections
}

\author{
S. M. E. Rahman, Joong Hyun Park and Deog-Hwan Oh* \\ Department of Food Science and Biotechnology, Institute of Bioscience and Biotechnology, \\ Kangwon National University, Chuncheon, Gangwon 200-701, Republic of Korea. \\ Accepted 15 July, 2011
}

\begin{abstract}
The study was designed to investigate bactericidal and fungicidal actions of salicid (pH: 6.7, ORP: 760 $\mathrm{mV}$, residual chlorine of 2 to $5 \mathrm{ppm}$ ) on hospital infections. Four of the most common opportunistic pathogens (Klebsiella pneumoniae, Staphylococcus aureus, Rhizopus oryzae, and Aspergillus fumigatus) were used for this study. Cultures were inoculated in $9 \mathrm{~mL}$ of salicid and incubated for $0.5,1$, $3,5,7$ and $10 \mathrm{~min}$ at room temperature $\left(23 \pm 2{ }^{\circ} \mathrm{C}\right)$. A dipping method was followed for this study. Untreated pathogens were treated as control. Compared to the untreated control, a reduction of 1.10 to $6.08 \log _{10} \mathrm{CFU} / \mathrm{mL}$ for aforementioned pathogens were recorded as the result of treatment with 2 and 5 $\mathrm{ppm}$ salicid, respectively. The highest bactericidal effect was found with $S$. aureus for $5 \mathrm{ppm}$ salicid with $0.5 \mathrm{~min}$ immerse time. Salicid treatment with $0.5 \mathrm{~min}$ dipping and $5 \mathrm{ppm}$ residual chlorine also reduced $K$. pneumoniae, $R$. oryzae, and $A$. fumigatus by $5.00,3.50$ and $2.63 \log _{10} \mathrm{CFU} / \mathrm{mL}$, respectively. Our findings showed that in each pathogen, efficacy of salicid decreased significantly $(p<0.05)$ with increased dipping time, from 0.5 to $10 \mathrm{~min}$ and there was significant difference $(p<0.05)$ observed between 2 and 5 ppm salicid treatment in reducing pathogens. The results indicate that salicid may be a useful disinfectant for hospital infections, but its clinical application has still to be evaluated.
\end{abstract}

Key words: Salicid, bactericidal and fungicidal effect, hospital infections.

\section{INTRODUCTION}

Hospital infections are a serious medical, social, and economic problem for public health services all over the world (Vorobjeva et al., 2004). K. pneumoniae, S. aureus, $R$. oryzae, and $A$. fumigatus are the most opportunistic human pathogens involved in hospital infections. $K$. pneumoniae is a major cause of nosocomial infections (DeChamps et al., 1991; Johnson et al., 1992). As a general rule, Klebsiella infections tend to occur in people with a weakened immune system. Many of these infections are obtained when a person is in the hospital for some other reason. The most common infection caused by Klebsiella bacteria outside the hospital is pneumonia. $S$. aureus is the most common organism responsible for postoperative wound infections (Wenzel and Perl, 1995) and a leading cause of septicaemia,

*Corresponding author. E-mail: deoghwa@kangwon.ac.kr. Tel: 82-33-250-6457. Fax: 82-33-250-6457. intravenous catheter-related infections and skin and softtissue infections. Auto-infection of surgical wounds by $S$. aureus is common, and is associated with considerable morbidity and represents an important medical and economic problem. $R$. oryzae is the most common cause of zygomycosis, a life-threatening infection that usually occurs in immunocompromised patients (Ibrahim et al., 2005). Infections caused by Aspergillus species have grown in importance in recent years (Pasqualotto, 2009). As most of the Aspergillus infections are caused by $A$. fumigatus, the majority of studies have focused on this species. Such pathogens are typically characterized by a wide variety of sources, ways, and factors of transmission, appearing in different types of clinics and preventive hospitals. In this context, the methods of asepsis and active chemical antisepsis are currently becoming increasingly important in terms of the prevention of hospital infections.

Salicid is the first potable product treating infectious disease on human mucosa and skin using its 


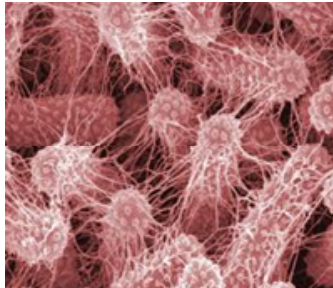

Klebsiella pneumoniae

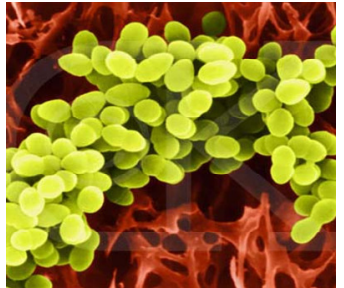

Staphylococcus aureus

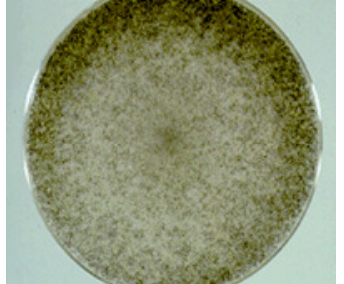

Rhizopus oryzae

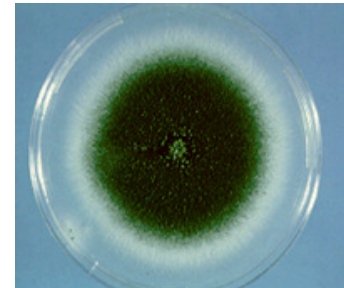

A. fumigatus

Figure 1. Challenge microorganism.

antimicrobial efficacy for bacteria, fungi and viruses. When electrolyzing brine with salicid, small sized chlorine bubbles are generated and this chlorine gas dissolves in the solution, producing the free chlorine. Salicid hardly change the $\mathrm{pH}$ value of used water, so it is the product available for medical use which can use hypochlorous acid which is a predominant species of free chlorine at the $\mathrm{pH}$ range of weak acidic and neutral. The free chlorine solution generated by salicid is below $5 \mathrm{ppm}$ which is allowed by WHO for drinking water and swimming pool water and also is safe to human mucosa. Accordingly, salicid is the first antiviral product which can be applied for human mucosa and is the first product which has antimicrobial efficacy for bacteria and fungi, simultaneously.

The objective of this study was to evaluate the bactericidal and fungicidal effect of salicid obtained in the salicid electrolysis device on common hospital pathogens under in vitro conditions.

\section{MATERIALS AND METHODS}

\section{Challenge microorganisms}

K. pneumoniae- ATCC 8724, S. aureus- ATCC 12488, R. oryzaeATCC 24794, A. fumigatus- ATCC 26430 (Figure 1).

\section{Media and reagents}

Tryptic Soy Agar (TSA), Tryptic Soy Broth (TSB), Potato Dextrose Agar (PDA), $0.85 \%$ saline solution (ss), Neutralizer used: $0.85 \%$ $\mathrm{Nacl}$ containing $0.5 \% \mathrm{Na}_{2} \mathrm{~S}_{2} \mathrm{O}_{3}$

\section{Laboratory equipments}

Sterile test tubes, Sterile flasks, Sterile Beaker, Sterile pipettes, Petridishes, Stopwatch, Incubator capable of maintaining $35^{\circ} \mathrm{C}$, Incubator capable of maintaining $25^{\circ} \mathrm{C}$, Pincer, Cheese gauge cloth, Haemocytometer, Microscope, Glass rod, Calibrated thermometers

\section{Inocula preparation}

K. pneumoniae and $S$. aureus stock cultures were transferred into tryptic soy broth (TSB) and incubated for $24 \mathrm{~h}$ at $35^{\circ} \mathrm{C}$. Following incubation, $10 \mathrm{ml}$ of each culture was sedimented by centrifugation (3000 $\mathrm{x} \mathrm{g}$ for $10 \mathrm{~min}$ ), washed and resuspended in $10 \mathrm{ml}$ of $0.1 \%$ peptone water $(\mathrm{pH} 7.1)$ to obtain a final cell concentration of $10^{9}$ $\mathrm{CFU} / \mathrm{mL}$. The bacterial population in each culture was confirmed by plating $0.1 \mathrm{ml}$ portions of appropriately diluted culture on tryptic soy agar (TSA) (Difco Laboratories) plates and incubating the plates at $35^{\circ} \mathrm{C}$ for $24 \mathrm{~h} .1 \mathrm{ml}$ of the suspension was used as the inoculum $\left(10^{9} \mathrm{CFU}\right)$.

The two fungal strains $A$. fumigatus and $R$. oryzae were inoculated from the stock culture onto PDA and incubated at $25^{\circ} \mathrm{C}$ for 10-15 days or until sporulation occurred. When the cultures appeared to be mature, the mycelial mats was removed from the surface of at least five plates and macerated with ss with a sterile glass rod. The suspension was filtered through sterile cheese gauge cloth to remove the hyphae. In order to remove any organic matter, each of the prepared fungi suspensions was washed in the same manner as described for the bacteria.

\section{Test agent preparation}

For each generation of the test material, one salicid packet was added to the test device containing $35 \mathrm{~mL}$ of sterile tap water $(\mathrm{pH}$ 7.0). The device was shaken 10 times. The generation button was activated by pressing the button and let it electrolysis for $20 \mathrm{~s}$. After $20 \mathrm{~s}$ the activation button was stopped manually, then the device was shaken 2-3 times and the product was immediately dispensed for testing. After 20 to $21 \mathrm{~s}$ electrolysis we got $2 \mathrm{ppm}$ salicid and in the same way after $44-45 \mathrm{~s}$ electrolysis we got $5 \mathrm{ppm}$ salicid $(\mathrm{pH}$ : 6.5-7.0, ORP: 760-775 mV).

\section{Test devices and material}

Salicid (device), serial no. 001170, Salicid (device), serial no. 001171, Salicid salt packet, (Executive Summary former salt 315 $\mathrm{mg}$ / saline $35 \mathrm{ml}$ ), DPD Free Chlorine Reagent (Figure 2).

\section{Test}

For each replicate, a $1 \mathrm{~mL}$ aliquot of prepared inoculum was added to a sterile test tube. Once the test material is generated, $9 \mathrm{~mL}$ of the prepared test agent was added to the tube containing $1 \mathrm{~mL}$ of the prepared inoculum; a timer started and the tube was mixed immediately. After each contact times, a $1 \mathrm{~mL}$ sample was transferred to a tube containing $9 \mathrm{~mL}$ of neutralizer. Serial ten-fold dilutions were performed in $0.85 \%$ ss dilution blanks. There were three replicates performed for each microorganism.

\section{Contact times}

$30 \mathrm{~s}, 1,3,5,7$ and $10 \mathrm{~min}$. 


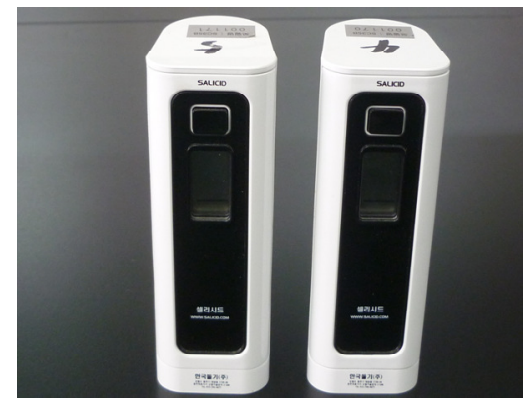

Salicid device

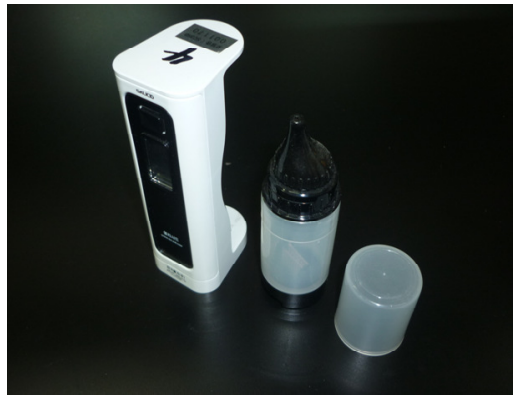

Dry cell

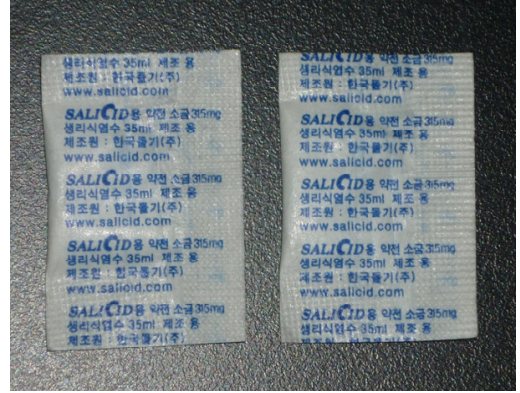

Salicid salt packet

Figure 2. Test devices.

\section{Temperature}

Ambient room temperature

\section{Incubation and enumeration}

Upon completion of the test, all plates were inverted and incubated for the appropriate time and temperature as follows: $k$. pneumoniae and $s$. aureus were incubated for 18 to $24 \mathrm{~h}$ at $35^{\circ} \mathrm{C}$. A. fumigatus and $R$. oryzae were incubated for $3-5$ days at $25^{\circ} \mathrm{C}$. Following incubation, all plates were removed from the incubator, the colonies were counted and the $\mathrm{CFU} / \mathrm{mL}$ at each contact time was determined.

\section{Statistical analysis}

For each treatment, the data from the independent replicate trials were pooled and the mean value and standard deviation were determined.

\section{RESULTS AND DISCUSSION}

The mean counts, percent reduction and $\log _{10}$ reduction per test material, contact time and organism are presented in Tables 1 to 4 . $\log _{10}$ reduction and percent reduction were calculated using the following equations:

Enumeration is expressed as colony-forming units $(\mathrm{CFU} / \mathrm{mL})$

\section{Average Initial Counts Control - Test Results}

X $100=$ Percent Reduction

Average Initial Counts Control

$\log _{10}$ (Average Initial Counts Control) - $\log _{10}$ (Test Results) $=\log _{10}$ Reduction

Cell suspensions of $K$. pneumoniae, $S$. aureus, $R$. oryzae and $A$. fumigatus were treated at RT $\left(23 \pm 2^{\circ} \mathrm{C}\right)$ for $0.5,1$, 3, 5, 7 and $10 \mathrm{~min}$ with Salicid. Salicid had major antibacterial activity compared to yeast and mould on different challenge microorganisms. Our results revealed that salicid containing $5 \mathrm{ppm}$ of residual chlorine was more effective $(p<0.05)$ than that of $2 \mathrm{ppm}$ salicid in reducing populations of bacterial and fungal strains regardless of dipping time. Reduction of bacterial count was ranged from 3.15 to $6.08 \log _{10} \mathrm{CFU} / \mathrm{mL}$ and 1.10 to $3.50 \log _{10} \mathrm{CFU} / \mathrm{mL}$ reduction was gained in yeast and mould, respectively. With the increased dipping time rate of log reduction was decreased. The available chlorine concentration (ACC) reduced with an increase in dipping time which could have resulted in lower reductions at increased dipping times. Sensitivity to sanitizers depends on pathogens' characteristics and properties of sanitizers. From our tested pathogens bacteria were more sensitive to salicid compared to fungi and $A$. fumigatus was more resistant to salicid treatment than other three pathogens. Chemical compounds such as formaldehyde, phenol, glutaraldehyde, tricresol and chloramines have shown bactericidal and fungicidal effects (Hegna and Clausen, 1988). However, most of these disinfectants are made from the dilution of condensed solutions, which in handling involves some risk and is troublesome. A disinfectant that is not produced from the dilution of a hazardous condensed solution is required for practical use.

In recent years, electrolyzed oxidizing water (EOW) has gained interest as a disinfectant used in agriculture, dentistry, medicine and food industry (Huang et al., 2008). An advantage of EOW is that it can be produced with tap water, with no added chemicals other than sodium chloride. EOW has been attracting as a disinfectant because of its strong microbicidal activities on a broad variety of bacterial pathogens (Venkitanarayanan et al., 1999). Moreover, EOW exerts fungicidal activity (Suzuki et al., 2002a, b). Xiong et al. (2010) reported that the $\mathrm{OH}$ radical $(\mathrm{OH})$ that exists in neutralized electrolyzed oxidizing water (NEW) and acidic electrolyzed oxidizing water (AcEW) was found to have an important fungicidal factor. However, the potential application of EOW is limited because of its low $\mathrm{pH}$ values $(\leq 2.7)$ and it corrosive characteristics. At this low $\mathrm{pH}$, dissolved $\mathrm{Cl}_{2}$ 
Table 1. In vitro inactivation of Klebsiella pneumoniae using salicid.

\begin{tabular}{|c|c|c|c|c|c|c|c|}
\hline \multirow{3}{*}{$\begin{array}{c}\text { Initial count } \\
\text { CFU/mL recovered }\end{array}$} & \multirow{3}{*}{$\begin{array}{l}\text { Dipping time } \\
\text { (min) }\end{array}$} & \multicolumn{6}{|c|}{ Calculation units } \\
\hline & & \multicolumn{2}{|c|}{ CFU/mL recovered } & \multicolumn{2}{|c|}{ Percent reduction } & \multicolumn{2}{|c|}{$\log _{10}$ reduction } \\
\hline & & $2 \mathrm{ppm}$ & $5 \mathrm{ppm}$ & $2 \mathrm{ppm}$ & $5 \mathrm{ppm}$ & $2 \mathrm{ppm}$ & $5 \mathrm{ppm}$ \\
\hline \multirow{6}{*}{$1.0 \times 10^{8}$} & 0.5 & $1.5 \times 10^{4} \pm 0.10$ & $1.0 \times 10^{3} \pm 0.06$ & 99.9850 & 99.9990 & $3.82^{\mathrm{a}}$ & $5.00^{b}$ \\
\hline & 1 & $1.6 \times 10^{4} \pm 0.09$ & $1.0 \times 10^{3} \pm 0.09$ & 99.9840 & 99.9990 & $3.80^{\mathrm{a}}$ & $5.00^{b}$ \\
\hline & 3 & $1.9 \times 10^{4} \pm 0.10$ & $1.5 \times 10^{3} \pm 0.20$ & 99.9810 & 99.9985 & $3.72^{\mathrm{a}}$ & $4.82^{b}$ \\
\hline & 5 & $2.8 \times 10^{4} \pm 0.18$ & $2.5 \times 10^{3} \pm 0.09$ & 99.9720 & 99.9975 & $3.55^{\mathrm{a}}$ & $4.60^{\mathrm{b}}$ \\
\hline & 7 & $5.5 \times 10^{4} \pm 0.10$ & $6.5 \times 10^{3} \pm 0.06$ & 99.9450 & 99.9935 & $3.26^{\mathrm{a}}$ & $4.19^{b}$ \\
\hline & 10 & $7.0 \times 10^{4} \pm 0.08$ & $1.1 \times 10^{4} \pm 0.13$ & 99.9300 & 99.9890 & $3.15^{\mathrm{a}}$ & $3.96^{b}$ \\
\hline
\end{tabular}

Values with different letters within the same column differ significantly at $p<0.05$.

Table 2. In vitro inactivation of Staphylococcus aureus using salicid.

\begin{tabular}{|c|c|c|c|c|c|c|c|}
\hline \multirow{3}{*}{$\begin{array}{c}\text { Initial count } \\
\text { CFU/mL recovered }\end{array}$} & \multirow{3}{*}{$\begin{array}{l}\text { Dipping time } \\
\qquad(\mathrm{min})\end{array}$} & \multicolumn{6}{|c|}{ Calculation units } \\
\hline & & \multicolumn{2}{|c|}{ CFU/mL recovered } & \multicolumn{2}{|c|}{ Percent reduction } & \multicolumn{2}{|c|}{$\log _{10}$ reduction } \\
\hline & & 2 ppm & 5 ppm & 2 ppm & $5 \mathrm{ppm}$ & 2 ppm & $5 \mathrm{ppm}$ \\
\hline \multirow{6}{*}{$1.2 \times 10^{8}$} & 0.5 & $3.5 \times 10^{2} \pm 0.10$ & $1.0 \times 10^{2} \pm 0.1$ & 99.9997 & 99.9999 & $5.54^{\mathrm{a}}$ & $6.08^{\mathrm{b}}$ \\
\hline & 1 & $4.0 \times 10^{2} \pm 0.10$ & $1.0 \times 10^{2} \pm 0.26$ & 99.9997 & 99.9999 & $5.48^{\mathrm{a}}$ & $6.08^{b}$ \\
\hline & 3 & $6.0 \times 10^{2} \pm 0.18$ & $1.5 \times 10^{2} \pm 0.17$ & 99.9995 & 99.9999 & $5.30^{\mathrm{a}}$ & $5.90^{\mathrm{b}}$ \\
\hline & 5 & $1.1 \times 10^{3} \pm 0.21$ & $2.0 \times 10^{2} \pm 0.18$ & 99.9991 & 99.9998 & $5.04^{a}$ & $5.78^{b}$ \\
\hline & 7 & $1.5 \times 10^{3} \pm 0.20$ & $3.0 \times 10^{2} \pm 0.25$ & 99.9988 & 99.9998 & $4.90^{\mathrm{a}}$ & $5.60^{b}$ \\
\hline & 10 & $2.0 \times 10^{3} \pm 0.18$ & $4.5 \times 10^{2} \pm 0.22$ & 99.9983 & 99.9996 & $4.78^{\mathrm{a}}$ & $5.43^{b}$ \\
\hline
\end{tabular}

Values with different letters within the same column differ significantly at $p<0.05$.

gas can be rapidly lost due to volatilization, adversely affecting human health and the environment. Moreover, the high acidity of EOW may cause the corrosion of equipment and consequently limit its practical application (Abadias et al., 2008; Guentzel et al., 2008). So, as an alternative to EOW we used salicid in our study. Salicid with a $\mathrm{pH}$ value of $6.5-7.0$, also known as slightly acidic low concentration electrolyzed water (SIALCEW), is commonly produced by electrolyzing a dilute salt solution $(0.9 \% \mathrm{NaCl})$ in a non-membrane electrolytic cell (Rahman et al., 2010). At a near-neutral $\mathrm{pH}$, the predominant chemical species is the highly biocidal hypochlorous acid species $(\mathrm{HOCl}$, approximately $95 \%)$. The advantage of salicid are numerous: non-corrosive due to near-neutral $\mathrm{pH}$, low current and minimum time required to produce it, it does not leave residuals due to low content of ACC (2 $5 \mathrm{mg} / \mathrm{L}$ ), comparatively inexpensive, and a less potential health hazard to the worker due to the lack of $\mathrm{Cl}_{2}$ off-gassing. To produce salicid, an apparatus is required that utilizes common salt and an electric source. Salicid can be produced at site, as the size of the machine is quite small. Therefore, the widely used EOW might be replaced by salicid as an effective and environmentally friendly sanitizer in medical use.

Based on our study this salicid can be recommended for use as a strong disinfectant for the equipment, and diagnostic and medical devices in hospitals. However, future clinical research has to be done under an in vivo system, in order to 
Table 3. In vitro inactivation of Rhizopus oryzae using salicid.

\begin{tabular}{|c|c|c|c|c|c|c|c|}
\hline \multirow{3}{*}{$\begin{array}{c}\text { Initial count } \\
\text { CFU/mL recovered }\end{array}$} & \multirow{3}{*}{$\begin{array}{l}\text { Dipping time } \\
\text { (min) }\end{array}$} & \multicolumn{6}{|c|}{ Calculation Units } \\
\hline & & \multicolumn{2}{|c|}{ CFU/mL recovered } & \multicolumn{2}{|c|}{ Percent reduction } & \multicolumn{2}{|c|}{$\log _{10}$ reduction } \\
\hline & & $2 \mathrm{ppm}$ & $5 \mathrm{ppm}$ & $2 \mathrm{ppm}$ & $5 \mathrm{ppm}$ & 2 ppm & $5 \mathrm{ppm}$ \\
\hline \multirow{6}{*}{$7.5 \times 10^{6}$} & 0.5 & $7.4 \times 10^{3} \pm 0.13$ & $2.4 \times 10^{3} \pm 0.09$ & 99.9013 & 99.9680 & $3.01^{\mathrm{a}}$ & $3.50^{\mathrm{b}}$ \\
\hline & 1 & $8.0 \times 10^{3} \pm 0.11$ & $2.5 \times 10^{3} \pm 0.01$ & 99.8933 & 99.9667 & $2.98^{\mathrm{a}}$ & $3.48^{\mathrm{b}}$ \\
\hline & 3 & $1.1 \times 10^{4} \pm 0.09$ & $3.6 \times 10^{3} \pm 0.08$ & 99.8533 & 99.9520 & $2.84^{\mathrm{a}}$ & $3.33^{\mathrm{b}}$ \\
\hline & 5 & $1.5 \times 10^{4} \pm 0.08$ & $5.3 \times 10^{3} \pm 0.04$ & 99.8000 & 99.9293 & $2.70^{\mathrm{a}}$ & $3.16^{\mathrm{b}}$ \\
\hline & 7 & $2.7 \times 10^{4} \pm 0.11$ & $1.2 \times 10^{4} \pm 0.09$ & 99.6400 & 99.8400 & $2.45^{\mathrm{a}}$ & $2.78^{b}$ \\
\hline & 10 & $4.8 \times 10^{4} \pm 0.08$ & $3.0 \times 10^{4} \pm 0.29$ & 99.3600 & 99.6000 & $2.20^{\mathrm{a}}$ & $2.41^{b}$ \\
\hline
\end{tabular}

Values with different letters within the same column differ significantly at $p<0.05$.

Table 4. In vitro inactivation of Aspergillus fumigatus using salicid.

\begin{tabular}{|c|c|c|c|c|c|c|c|}
\hline \multirow{3}{*}{$\begin{array}{c}\text { Initial count } \\
\text { CFU/mL recovered }\end{array}$} & \multirow{3}{*}{$\begin{array}{l}\text { Dipping time } \\
\qquad(\min )\end{array}$} & \multicolumn{6}{|c|}{ Calculation Units } \\
\hline & & \multicolumn{2}{|c|}{ CFU/mL recovered } & \multicolumn{2}{|c|}{ Percent reduction } & \multicolumn{2}{|c|}{$\log _{10}$ reduction } \\
\hline & & $2 \mathrm{ppm}$ & 5 ppm & $2 \mathrm{ppm}$ & $5 \mathrm{ppm}$ & 2 ppm & $5 \mathrm{ppm}$ \\
\hline \multirow{6}{*}{$2.4 \times 10^{7}$} & 0.5 & $2.6 \times 10^{5} \pm 0.05$ & $5.6 \times 10^{4} \pm 0.06$ & 98.9167 & 99.7667 & $1.97^{\mathrm{a}}$ & $2.63^{\mathrm{b}}$ \\
\hline & 1 & $3.0 \times 10^{5} \pm 0.03$ & $6.0 \times 10^{4} \pm 0.03$ & 98.7500 & 99.7500 & $1.90^{\mathrm{a}}$ & $2.60^{b}$ \\
\hline & 3 & $4.0 \times 10^{5} \pm 0.26$ & $9.0 \times 10^{4} \pm 0.05$ & 98.3333 & 99.6250 & $1.78^{\mathrm{a}}$ & $2.43^{b}$ \\
\hline & 5 & $6.0 \times 10^{5} \pm 0.20$ & $1.4 \times 10^{5} \pm 0.11$ & 97.5000 & 99.4167 & $1.58^{\mathrm{a}}$ & $2.23^{b}$ \\
\hline & 7 & $1.0 \times 10^{6} \pm 0.23$ & $1.8 \times 10^{5} \pm 0.08$ & 95.8333 & 99.2500 & $1.38^{\mathrm{a}}$ & $2.13^{b}$ \\
\hline & 10 & $1.9 \times 10^{6} \pm 0.10$ & $2.5 \times 10^{5} \pm 0.04$ & 92.0833 & 98.9583 & $1.10^{\mathrm{a}}$ & $1.98^{b}$ \\
\hline
\end{tabular}

Values with different letters within the same column differ significantly at $p<0.05$.

evaluate the stability of salicid under operating conditions and its safety for medical personnel and patients.

\section{ACKNOWLEDGEMENT}

The authors thank the Dolki Korea Limited (Wonju, Gangwon-Do, Korea) for providing the salicid device.

\section{REFERENCES}

Abadias M, Usall J, Oliveira M, Alegre I, Viñas I (2008). Efficacy of neutral electrolyzed water (NEW) for reducing microbial contamination on minimally processed vegetables. Int. J. Food Microbiol., 123: 151-158.

DeChamps C, Rouby D, Guelon D (1991). A case-control study of an outbreak of infections caused by Klebsiella pneumoniae strains producing CTX-1 (TEM-3) beta lactamase. J. Hosp. Infect., 18: 5-13.

Guentzel JL, Lam KL, Callan MA, Emmons SA, Dunham VL (2008). Reduction of bacteria on spinach, lettuce, and surfaces in food service areas using neutral electrolyzed oxidizing water Food Microbiol, 25: 36-41.

Huang Y-R, Hung Y-C, Hsu S-Y, Huang Y-W, Hwang D-F (2008). Application of electrolyzed water in the food industry. Food Cont., 19: 329-345.

Hegna IK, Clausen OG (1988). An investigation of the bactericidal and fungicidal effects of certain disinfectants by use of a capacity test. Ann. Inst. Pasteur Microbiol., 139: 473-483.

Ibrahim AS, Spellberg B, Avanessian V, Fu Y, Edwards Jr JE (2005). Rhizopus oryzae adheres to, is phagocytosed by, and damages endothelial cells in vitro. Infect. Immun., 73: 778-783.

Johnson AP, Weinbren MJ, Ayling-Smith B, DuBois SK, 
Amyes SGB, George RC (1992). Outbreak of infection in two UK hospitals caused by a strain of Klebsiella pneumonia resistant to cefotaxime and ceftazidime. J. Hosp. Infect., 20: 97-103.

Pasqualotto AC (2009). Differences in pathogenicity and clinical syndromes due to Aspergillus fumigatus and Aspergillus flavus. Med. Mycol., 47 suppl 1: S261-270.

Rahman SME, Ding T, Oh D-H (2010). Effectiveness of low concentration electrolyzed water to inactivate foodborne pathogens under different environmental conditions. Int. J. Food Microbiol., 139: 147-153.

Suzuki T, Itakura J, Watanabe M, Ohta M, Sato Y, Yamaya Y (2002a). Inactivation of staphylococcal enterotoxin $A$ with an electrolyzed anodic solution. J. Agric. Food Chem., 50: 230-234.

Suzuki T, Noro T, Kawamura Y, Fukunaga K, Watanabe M, Ohta M., Sugiue H., Sato Y, Kohno M, Hotta K (2002b). Decontamination of Aflatoxin-forming fungus and elimination of Aflatoxin mutagenicity with electrolyzed $\mathrm{NaCl}$ anode solution. J. Agric. Food Chem., 50: 633-641.
Venkitanarayanan KS, Ezeike GO, Hung Y-C, Doyle MP (1999). Efficacy of electrolyzed oxidizing water for inactivating Escherichia coli 0157:H7, Salmonella enteritidis, and Listeria monocytogenes. Appl. Environ. Microbiol., 65: 4276-4279.

Vorobjeva NV, Vorobjeva LI, Khodjaev EY (2004). The bactericidal effects of electrolyzed oxidizing water on bacterial strains involved in hospital infections. Artif. Organs., 28: 590- 592.

Wenzel RP, Perl TM (1995). The significance of nasal carriage of Staphylococcus aureus and the incidence of postoperative wound infection. J. Hosp. Infect., 31: 13-24.

Xiong K, Liu H, Liu R, Li L (2010). Differences in fungicidal efficiency against Aspergillus flavus for neutralized and acidic electrolyzed oxidizing waters. Int. J. Food Microbiol., 137: 67-75. 